\title{
СИСТЕМА ГОСУДАРСТВЕННЫХ ЗАКУПОК В РОССИЙСКОЙ ФЕДЕРАЦИИ НА СОВРЕМЕННОМ ЭТАПЕ
}

\author{
(c) 2020 Хромов Иван Евгеньевич \\ кандидат экономических наук, \\ старший научный сотрудник, Лаборатория микроэкономического анализа и моделирования \\ Центральный экономико-математический институт РАН, Россия, Москва \\ E-mail:khromov_gaugn@mail.ru
}

В настоящее время в Российской Федерации совершенствуется система государственных закупок. В статье описаны основные направления реформирования отечественной системы государственных закупок. Также в работе охарактеризованы основные участники контрактной системы и основные цели осуществления государственных закупок.

Ключевые слова: сокращение издержек, управление предприятием, финансовое планирование, государственные закупки, контрактная система, прогнозирование, открытый конкурс.

Государственные закупки продукции, работ, услуг оказывают существенное влияние на регулирование экономики в нашей стране. С целью осуществления закупок для государственных нужд необходимы разработка и утверждение целевых программ и создание специальных государственных компаний, которые занимаются размещением государственных заказов.

Российская экономика находится сейчас на этапе реализации глобальной реформы в сфере государственных закупок, в которой можно выделить три основных направления, представленных на рис. 1 [9].

Под институциональной основой реформы понимаются соответствующие федеральные законы, которые устанавливают принципы организации и управления контрактными отноше- ниями, а именно:

- в сфере размещения и реализации государственного и муниципального заказа (Федеральный закон от 05.04.2013 г. № 44-Ф3 «О контрактной системе в сфере закупок товаров, работ, услуг для обеспечения государственных и муниципальных нужд») [4];

- в сфере формирования системы оборонного заказа (Федеральный закон от 29.12.2012 г. № 275 -ФЗ «О государственном оборонном зака3e) [3];

- в сфере закупок хозяйствующих субъектов государственного сектора экономики (Федеральный закон от 18.07.2011 г. № 223-ФЗ «О закупках товаров, работ, услуг отдельными видами юридических лиц») [2].

Следует отметить, что под действие зако-

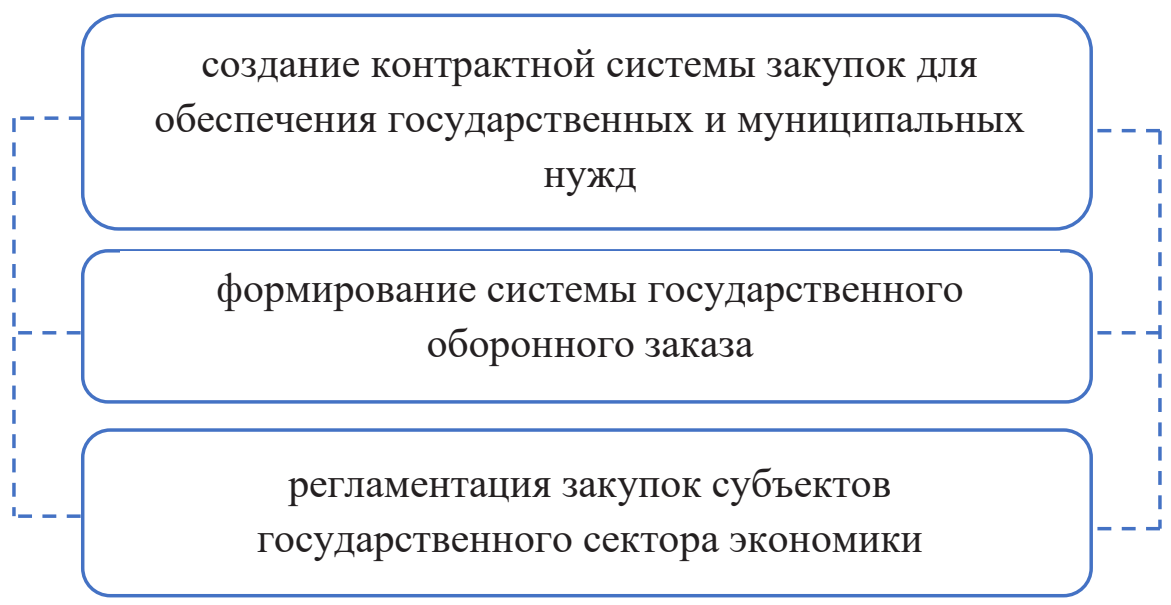

Puc. 1. Направления реализации реформы в сфере государственных закупок 
на № 223-Ф3 попадает закупочная деятельность государственного сектора экономики. К нему относятся следующие компании: государственные корпорации и государственные компании; субъекты естественных монополий; организации, осуществляющие регулирование теплоснабжения, водоснабжения; государственные и муниципальные общества, в уставном капитале которых доля участия РФ, субъекта РФ или муниципального образования в совокупности превышает пятьдесят процентов; дочерние хозяйственные общества, в уставном капитале которых более пятидесяти процентов долей в совокупности принадлежит всем указанным выше юридическим лицам [2].

Важной датой в регулировании контрактных отношений и закупок принято считать 1 января 2014 года, ведь именно с этого момента вступил в силу Федеральный закон от 05.04.2013 г. № 44Ф3 «О контрактной системе в сфере закупок товаров, работ, услуг для обеспечения государственных и муниципальных нужд».

Следует отметить, что в полном объеме указанный закон вступил в силу с 1 января 2017 г., внеся существенные изменения в системе государственных закупок.

В первую очередь перед заказчиком закупки теперь стоит необходимость обоснования самой закупки, приоритет в максимальном снижении цены контракта ушел в прошлое. Кроме того, оценке подлежит результативность закупки в обеспечении закупочной деятельности для государственных и муниципальных нужд. При этом акцент устанавливается именно на результат, полученный от ее размещения, а не на результат в виде суммы средств, направленных на размещение закупки.

Законом ввелись новые способы осуществления закупочных процедур, а именно: конкурс с ограниченным участием, двухэтапный конкурс и запрос предложений. Открытый аукцион проводится только в форме электронного аукциона.

Следует отметить, что для уже заключенных контрактов были установлены особенности по их исполнению. Появились изменения в правилах по определению начальной цены государственного контракта, в правилах оценки заявок на участие в государственных закупках. Внесение изменений в государственные контракты и их расторжение, надзор за деятельностью государственных и муниципальных заказчиков Закон так же не обошел стороной.
При этом сферы регулирования Закона о закупках и Закона № 223-Ф3 не пересекаются. Но закупочная деятельность бюджетных учреждений и унитарных предприятий является исключением из правил. Все зависит от источника расходования средств и от иных обстоятельств. Следовательно, они могут попадать под действие как Закона о закупках № 44-ФЗ, так и Закона № 223-Ф3 [6].

Нормативно-правовое регулирование контрактной системы в сфере закупок лежит на стыке гражданского, административного и финансового права, образуя тем самым отдельный самостоятельный правовой институт.

На правительственном уровне для исполнения норм Закона о закупках № 44-ФЗ принято более пятидесяти постановлений Правительства Российской Федерации. При этом федеральные органы исполнительной власти могут регулировать отдельные вопросы контрактной системы. К таким органам можно отнести Министерство экономического развития России и Министерство финансов, Казначейство России и Федеральную антимонопольную службу.

Отношения в сфере закупочной деятельности помимо вышеуказанных органов власти могут регулироваться органами государственной власти субъектов РФ и органами местного самоуправления. В этом случае должен соблюдаться принцип единства контрактной системы: правовые акты таких органов должны соответствовать федеральным нормативным правовым aктам.

Нельзя обойти стороной Бюджетный кодекс РФ, который содержит несколько правовых норм, посвященных регулированию государственного и муниципального заказа, заключению государственного и муниципального контракта. Согласно статье 72 Бюджетного кодекса РФ, из этих правовых норм вытекает необходимость конкурсного подхода к размещению заказов для государственных и муниципальных нужд [1].

В сфере государственных закупок в Российской Федерации регулируются следующие процедуры:

- планирование закупок товаров, работ, услуг;

- порядок определения поставщиков (подрядчиков, исполнителей);

- порядок заключения государственных и муниципальных контрактов;

- отдельные особенности исполнения кон- 
трактов;

- мониторинг закупок товаров, работ, услуг;

- аудит в сфере закупок товаров, работ, услуг;

- контроль в сфере закупок.

Для реализации целей настоящего Федерального закона были введены и используются на данный момент следующие основные понятия:

1) контрактная система в сфере закупок товаров, работ, услуг для обеспечения государственных и муниципальных нужд - это совокупность участников контрактной системы в сфере закупок (структура представлена на рис. 2) [4], которые с помощью единой информационной системы (ЕИС) в сфере закупок осуществляют действия, направленные на обеспечение государственных и муниципальных нужд. При этом все действия должны соответствовать принятому в Российской Федерации законодательству и иным нормативным правовым актам, существующих в контрактной системе сферы закупок [5];

2) определение поставщика (подрядчика, исполнителя) - совокупность действий, которые осуществляются заказчиками, начиная с момента размещения извещения об осуществлении закупки товара, работы, услуги либо в отдельных случаях, которые установлены настоящим Федеральным законом, с направления приглашения принять участие в определении поставщика (подрядчика, исполнителя). Завершаются вышеуказанные действия процедурой заключения контракта. Следует отметить, что раньше под обозначение этой совокупности действий попадал термин «размещение заказов» [5];

3) закупка товара, работы, услуги для обеспечения государственных или муниципальных нужд - совокупность действий заказчика, которые направлены на обеспечение государственных или муниципальных нужд в соответствии с порядком, установленном законом о закупках;

4) открытый конкурс - конкурс, при котором информация о закупке размещается в открытом доступе в единой информационной системе в виде извещения о проведении такого конкурса заказчиком неограниченному кругу лиц, при этом к конкурсной документации и к участникам закупки предъявляются единые требования [5];

5) закрытый способ определения поставщиков (подрядчиков, исполнителей) - закрытый конкурс, закрытый конкурс с ограничен- ным участием, закрытый двухэтапный конкурс, закрытый аукцион, при которых информация о закупках направляется заказчиком ограниченному кругу лиц в виде приглашений принять участие в закрытых способах определения поставщиков (подрядчиков, исполнителей) [7]. При этом важным условием будет являться то, что этот круг лиц должен соответствовать всем требованиям к участникам закупок и быть способным осуществить поставки товаров, выполнение работ, оказание услуг, являющихся объектами закупок [11];

6) участник закупки - любое юридическое или физическое лицо, которое зарегистрировано в качестве индивидуального предпринимателя. На признание юридического лица участником закупки не влияют ни его организационноправовая форма, ни форма собственности, ни место его нахождения, а также место происхождения его капитала;

7) совокупный годовой объем закупок - утвержденный на соответствующий финансовый год общий объем финансового обеспечения для осуществления заказчиком закупок. Утверждение вышеуказанного объема необходимо для оплаты контрактов, заключенных до начала финансового года, которые при этом подлежат оплате в текущем финансовом году;

8) план закупок - это документ, который содержит сведения о закупке товаров, работ, услуг, необходимость в которых формирует потребность по формированию стратегии по проведению закупочных процедур. Этот план охватывает временной период в три года;

9) план-график - это документ, который содержит сведения о мероприятиях в сфере закупок, условиях их исполнения, охватывающий временной период в один год;

10) НМЦК - высшая (максимальная) цена или другими словами - верхний предел, указанный заказчиком в извещении, документации о закупке и приглашении принять участие в закупке, по которому в будущем будет заключен контракт;

11) заказчик - государственный или муниципальный заказчик либо бюджетное учреждение, осуществляющее закупки;

12) государственный контракт - договор, заключенный от имени Российской Федерации, субъекта Российской Федерации для обеспечения государственных нужд;

13) муниципальный контракт - договор, за- 


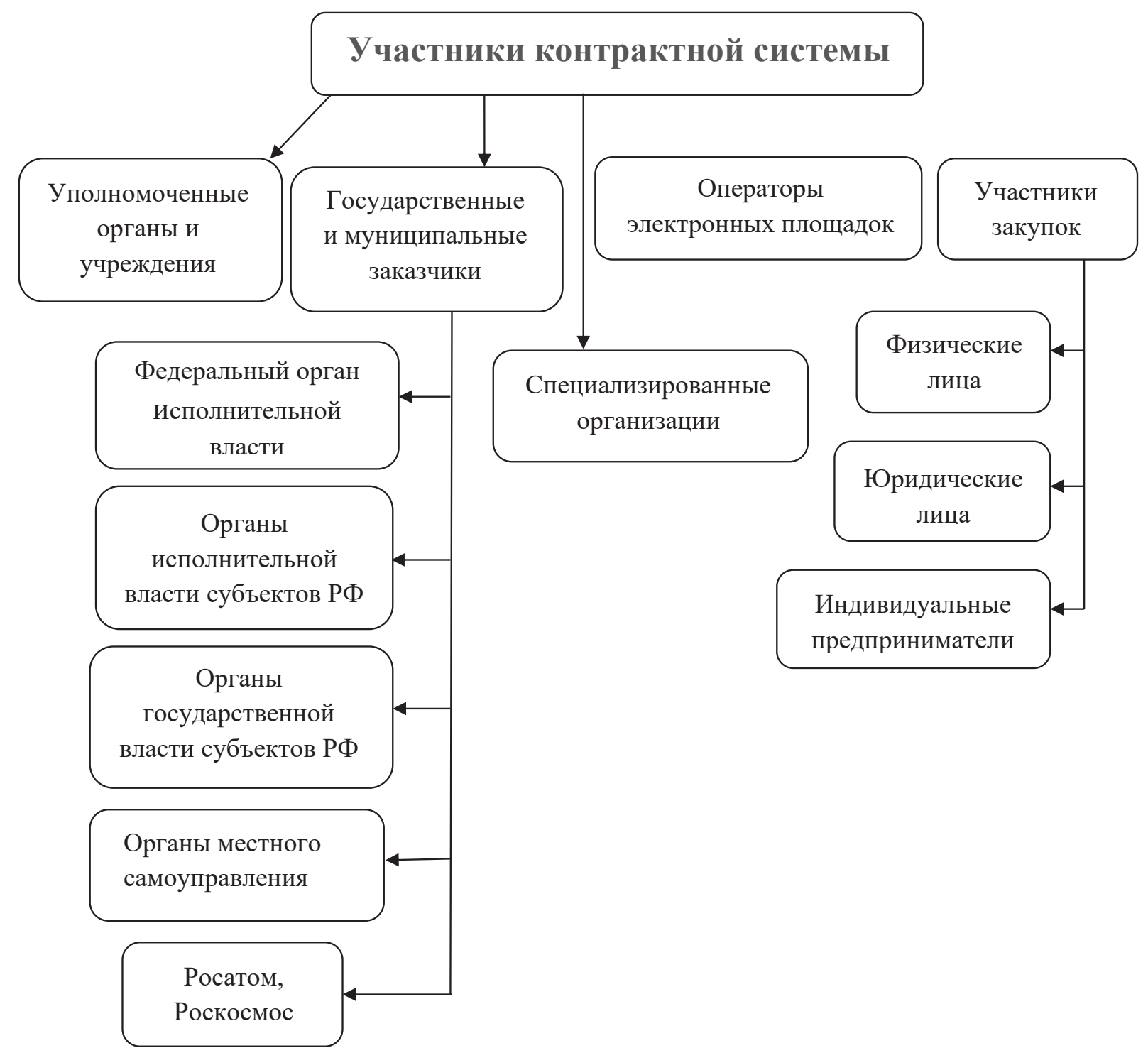

Puc. 2. Участники контрактной системы в сфере закупок РФ

ключенный от имени муниципального образования для обеспечения муниципальных нужд;

14) единая информационная система в сфере закупок (ЕИС) - совокупность информации, которая содержится в базах данных, информационных технологиях и технических средствах, обеспечивающих формирование, обработку, хранение этой информации;

15) федеральный орган исполнительной власти по регулированию контрактной системы в сфере закупок - федеральный орган исполнительной власти, который уполномочен на разработку государственной политики и регулирование в сфере закупок по нормативно-правовому принципу;

16) контрольный орган в сфере закупок федеральный орган исполнительной власти, ор- ган исполнительной власти субъекта Российской Федерации, орган местного самоуправления муниципального района или городского округа, уполномоченные на осуществление контроля в сфере закупок. Для обеспечения федеральных нужд в сфере осуществления государственного оборонного заказа контроль (надзор) возложен на федеральный орган исполнительной власти [10];

17) орган исполнительной власти субъекта Российской Федерации по регулированию контрактной системы в сфере закупок - орган, уполномоченный на обеспечение реализации государственной политики в сфере закупок для обеспечения нужд субъекта Российской Федерации и организации мониторинга закупок;

18) экспертиза - это оценка экспертами, 
экспертными организациями конкурсной документации, заявок на участие в проведении закупочных процедур, которая осуществляется для проверки полученных результатов в ходе их проведения на соответствие условиям контракта [4].

Контрактную систему как любую систему следует рассматривать в качестве связанных между собой элементов, которые образуют единое целое в сфере закупочной деятельности. Основополагающими принципами такой системы являются:

1) Принцип открытости и прозрачности информации о контрактной системе в сфере закупок: смысл этого принципа заключается в том, что доступ к информации о состоянии закупочной деятельности в России абсолютно открытый и доступный, при этом можно с уверенностью говорить о правдивости, полноте и достоверности представленных данных в сфере закупок. Всю информацию легко найти на официальном сайте единой информационной системы (ЕИС), на котором публикуются все актуальные сведения о закупочных процедурах.

2) Принцип обеспечения конкуренции: участники закупок в контрактной системе находятся между собой в отношениях ценовой и неценовой конкуренции. Вышеуказанный принцип создает равные для всех участников условия, обеспечивая тем самым здоровую и добросовестную конкуренцию. Это значит, что в нашей стране ограничение конкуренции не допустимо, так же не должно быть каких-либо оснований для ограничения количества участников закупок. Следует отметить, что поставщиком (подрядчиком, исполнителем) по действующему законодательству может стать любое заинтересованное в этом лицо.

3) Принцип профессионализма заказчиков: сфера закупок целиком и полностью строится на деятельности заказчиков, специализированных организаций и контрольного органа в сфере закупок. Важно, чтобы уровень профессионализма и квалификации специалистов, привлекаемых в контрактную систему, соответствовал всем требованиям. Для развития и поддержания теоретических знаний и практического опыта у таких специалистов должны приниматься все необходимые меры со стороны заказчиков и специализированных организа- ций, ведь за счет этого повышается уровень их квалификации в закупочной деятельности.

4) Принцип стимулирования инноваций: при организации и осуществлении закупок для государственных и муниципальных нужд заказчики должны ставить в приоритет такие важные критерии как инновационность и высокотехнологичность товаров, работ и услуг. Продукция может быть отнесена к инновационной в соответствии с нормативно-правовыми актами, установленными органами исполнительной власти на федеральном уровне.

5) Принцип единства контрактной системы в сфере закупок: для предупреждения разногласий и расхождений в контрактной системе сферы закупок предусмотрены единые принципы и подходы, на основании которых осуществляется закупочная деятельность на государственном и муниципальном уровнях.

6) Принцип ответственности за результативность обеспечения государственных и муниципальных нужд, эффективности осуществления закупок: все участники закупочных процедур должны быть нацелены на результат, а именно - на успешное проведение закупок для государственных и муниципальных нужд с достижением наибольшей эффективности. Следует помнить так же о том, что планирование и осуществление закупок должно исходить из необходимости соблюдения требований законодательства, принятого в Российской Федерации в сфере закупок. Все без исключения государственные органы и учреждения несут персональную ответственность за соблюдение нормативно-правовой системы [8].

Обеспечение федеральных нужд, нужд субъектов Российской Федерации и муниципальных нужд при осуществлении закупочной деятельности предполагает реализацию следующих целей, которые ставят перед собой заказчики, именно они представлены на рис. 3 [4].

Строгое регламентирование процедуры проведения закупок в соответствии с Законом о закупках, обозначение четких принципов и следование вышеуказанным целям помогает достичь заказчикам их конечную цель - любая закупка должна быть направлена на целевое и экономное расходование необходимых средств на обеспечение нужд заказчиков на любом уровне. 


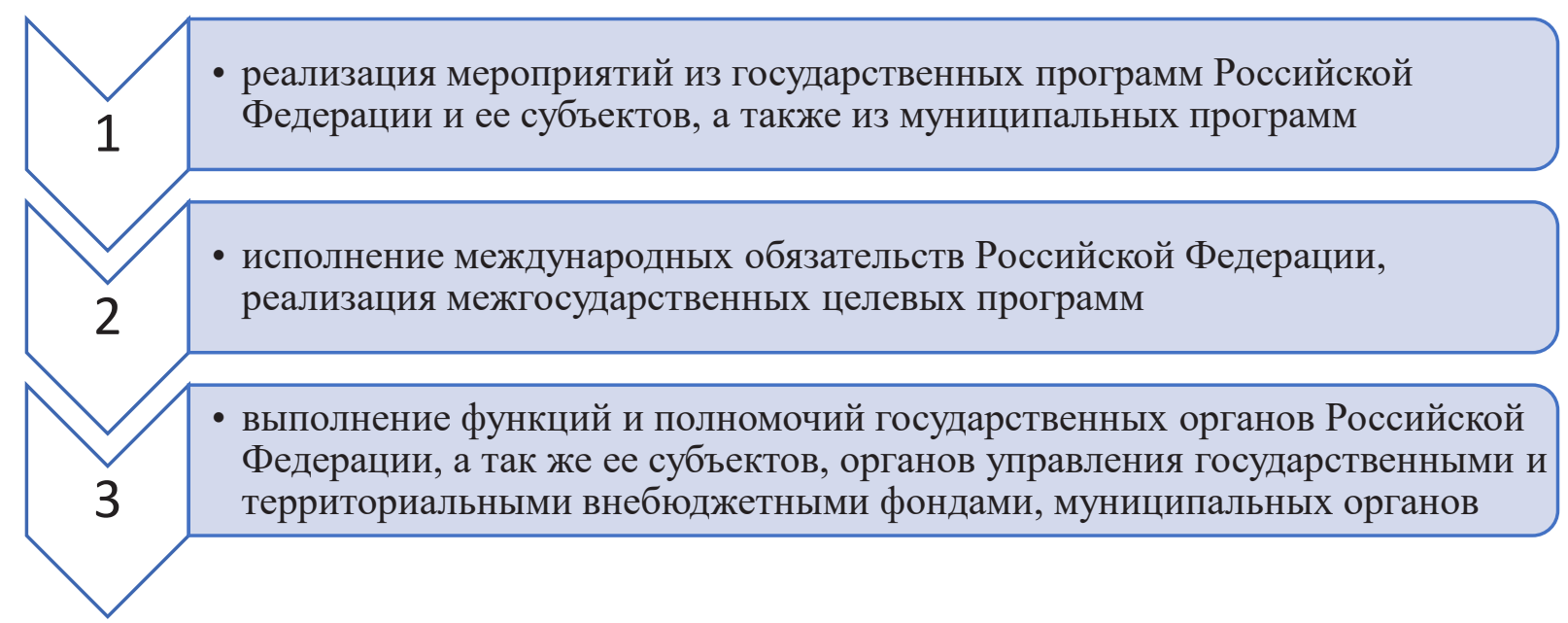

Рис. 3. Цели осуществления закупок

\section{Библиографический список}

1. Бюджетный кодекс Российской Федерации от 31.07.1998 № 145-Ф3 (ред. от 02.08.2019) (с изменениями и дополнениями, вступившими в силу с 01.09.2019) [Электронный ресурс]: доступ из справочно-правовой системы «Консультант Плюс».

2. Федеральный закон от 18.07.2011 № 223-Ф3 «О закупках товаров, работ, услуг отдельными видами юридических лиц» [Электронный ресурс]: доступ из справочно-правовой системы «Консультант Плюс».

3. Федеральный закон «О государственном оборонном заказе» от 29.12.2012 № 275-ФЗ [Электронный ресурс]: доступ из справочно-правовой системы «Консультант Плюс».

4. Федеральный закон от 05.04.2013 г. № 44-Ф3 (в ред. от 02.07.2013) «О контрактной системе в сфере закупок товаров, работ, услуг для обеспечения государственных и муниципальных нужд» [Электронный ресурс]: доступ из справочно-правовой системы «Консультант Плюс».

5. Борзенко Ю.А., Косарев К.В. Комментарий к Федеральному закону от 05.04.2013 № 44-ФЗ «О контрактной системе в сфере закупок товаров, работ, услуг для обеспечения государственных и муниципальных нужд»/ ФКОУ ВО Кузбасский ин-т ФСИН России, 2017 [Электронный ресурс]: Российская государственная библиотека.

6. Иванова В. Плюсы и минусы нового «закона о госзакупках»/ Сайт сетевого издания KONKURENT.RU. Интернет-источник - https://konkurent.ru/article/12225, 2014.

7. Кури Н.А. Порядок заключения договоров и структура договорных связей в государственных и муниципальных закупках (монография). - «Юстицинформ», 2018 г.

8. Нестерович Н. В. Прокьюремент. Принципы организации закупки продукции для государственных нужд / Конкурсные Торги № 9, с. 44-46, 1998.

9. Смотрицкая И. И. Институт закупок в Российской экономике: драйверы и барьеры развития/ Журнал «Вестник» Института экономики РАН. Интернет-источник - https:/cyberleninka.ru/article/n/institut-zakupok-vrossiyskoy-ekonomike-drayvery-i-bariery-razvitiya, 2014.

10. Федякина О.В. Постатейный комментарий к Федеральному закону «О закупках товаров, работ, услуг отдельными видами юридических лиц» от 18.07.2011 г. № 223-ФЗ.- «Право Доступа», 2018 г. [Электронный ресурс]: доступ из справочно-правовой системы «Гарант».

11. Хрипко Т.В.Анализ дополнительных требований к участникам закупки отдельных видов товаров, работ, услуг в строительной отрасли/ статья сборника «Научное обозрение 13-2016» [Электронный ресурс] Официальный сайт издательского дома «Наука образования» / www.sced.ru. 